\title{
The Application of the Conceptual Change Learning Model Combined with Predict-Observe-Explain to Overcome Student Misconceptions on Chemical Bonds
}

\author{
Grafiddin Rahmat, Hasan Muhammad, Rahmatan Hafnati* \\ Science Education Study Program, Postgraduate Program \\ Syiah Kuala University \\ Banda Aceh, Indonesia \\ hafnati_rahmatan@unsyiah.ac.id
}

\begin{abstract}
A misconception is a concept differing from experts' explanation, resulting in confusion among students. This study aims to apply the conceptual change learning model with a combination of predict-observe-explain to overcome students' misconceptions about the concept of chemical bonds. The research method was quasi-experimental. The samples were186 students at MAN (Islamic State Senior High School) Banda Aceh. Students' chemical bonding misconceptions were identified by the four-tier test, and data were then analyzed by the MannWhitney test. The results showed a decrease in misconceptions by 0.64 (medium) and 0.05 (low) in the experimental and control classes. Data analysis results showed a significant difference in the decrease of misconceptions between the experimental and control class. This implies that the conceptual change learning model combined with predict-observer-explain can reduce student misconceptions on chemical bonding.
\end{abstract}

Keywords-misconception, conceptual change model, predictobserver-explain model, chemical bonding

\section{INTRODUCTION}

Misconception is common in education. Many researchers have studied about misconception and tried to solve this problem. Several examples of misconception studies are in the concept of physical and chemical change [1], organic chemistry [2], and photocatalyst [3]. Kay and Yin [4] revealed some aspects causing misconception, including: First, the teachers do not realise about misconception even though they have taught students for years, Second students feel confident in their understanding, Third the explanation of the concept is not representative, so it tends to be excessive, Fourth inappropriate analogy by the teachers, and Fifth there is an ambiguous meaning of the concept. Previous studies have identified misconception in chemistry such as misconception analysis of chemical bonds $[5,6,7,8,9,10,11,12,13]$, redox reactions [14], titration [15], covalent bonds [16], ionic bonds [17], covalent and octet bonds [18], hybridization [19], chemical equilibrium [20, 21] and chemical kinetics [22,23]. One of the students' misconceptions about chemical bonds is that they cannot accurately describe the ionic and covalent bonds [2 4]. For example, most students stated that $\mathrm{KOH}$ and $\mathrm{NaNO}_{3}$ compound is ionic or covalent bonds. However, the correct answer is that both are covalent bonds as well as ionic ones. The impact of misconception can also affect students' learning outcomes. It can be seen from the 2017 National Examination (UN) data for chemistry subject. Aceh province ranked six out of 34 provinces with an average score of chemistry subject was 53.36. Banda Aceh, in particular, had the highest average of UN chemistry score by 87.50 with a percentage of $5.41 \%$.

One of the solutions in overcoming chemical bonds misconception is the implementation of Conceptual Change (CC) learning model [25]. The CC is a constructed learning model and has several stages in knowledge building [26].

Muis et al [27] stated that the reduction of misconceptions towards students with a sample of 120 people who were given the CC learning model treatment showed a significant impact in influencing their conceptual understanding. Chen and She [28] prove that the development of arguments or ideas for students in understanding concepts based on the theory of experts through the $\mathrm{CC}$ model is better than the use of conventional models, so that the misconceptions that exist in students can be corrected. Research by Novak et al [29] states that the use of the $\mathrm{CC}$ framework during learning can reduce students' misconceptions and understanding of the concepts formed can last in the long term. Ceylon and Yalcin [30] analyzed the impact of improving misconceptions through CC on the success rates of students in 57 students, namely: first the success rate of students increased after treatment and second student confidence increased from "self-confidence" to "Absolute confidence". They also suggest using CC with a mix of learning strategies such as simulation, analogy, and concept maps. The research of Sahin et al [31] shows that the CC model can reduce students' misconceptions about the concept of 
celestial bodies for 22 students with a pre-experimental research design.

In addition to this model, the POE (Predict Observe Explain) learning model is also often used to increase students' understanding. Usmeldi [32] research results show that the POE model is very effective in increasing students' mastery of concepts and competencies developed through learning modules. Most of the students gave very good responses, Usmeldi [32] suggested that the POE model be used in science material with research-based implementation. The data obtained shows that the use of POE can increase the understanding of the teacher's concept by $28.7 \%$, thus avoiding misconceptions. However, these two learning models are rarely used together in overcoming misconception. It is interesting since they affect solving misconception. The CC and POE models can restructure existing concepts with new information. Therefore, this study implemented the CC learning model with POE in reducing students' misconceptions of chemical bonds.

\section{MethodS}

This study was conducted on 19 September 2019 using a quasi-experimental research method to determine the decrease of chemical bonds misconception by using $\mathrm{CC}$ and POE models. The population in this study was all students of grade X-MIA MAN Banda Aceh such as MAN 1, MAN 2, and MAN 3. MAN 1 Banda Aceh has 265 students divided into 5 classes. MAN 2 Banda Aceh has 3 classes with 110 students. Meanwhile, MAN 3 Banda Aceh has 116 students, divided into 3 classes. The sample was determined by using purposive sampling technique while looking at the percentage of misconception through the four-tier test instrument on chemical bonds concept based on table 1 .

TABLE I. STUDENT CONCEPT CATEGORY

\begin{tabular}{|c|c|c|c|c|c|}
\hline \multirow[b]{2}{*}{$\begin{array}{c}\text { Comb } \\
\text { inatio } \\
\text { n No. }\end{array}$} & \multirow[b]{2}{*}{ Category } & \multicolumn{4}{|c|}{ Combination Answer } \\
\hline & & $\begin{array}{c}\text { Answe } \\
r\end{array}$ & $\begin{array}{c}\text { Confiden } \\
\text { ce rating } \\
\text { Answer }\end{array}$ & $\begin{array}{c}\text { Reaso } \\
n\end{array}$ & $\begin{array}{c}\text { Confidenc } \\
\text { e rating } \\
\text { Reason }\end{array}$ \\
\hline 1 & \multirow{4}{*}{ Misconception } & True & Sure & False & Sure \\
\hline 2 & & True & Not sure & False & Sure \\
\hline 3 & & False & Sure & False & Sure \\
\hline 4 & & False & Not sure & False & Sure \\
\hline 5 & \multirow{9}{*}{$\begin{array}{l}\text { Lack of } \\
\text { knowledge }\end{array}$} & True & Sure & True & Not sure \\
\hline 6 & & True & Sure & False & Not sure \\
\hline 7 & & True & Not sure & True & Sure \\
\hline 8 & & True & Not sure & True & Not sure \\
\hline 9 & & True & Not sure & False & Not sure \\
\hline 10 & & False & Sure & True & Not sure \\
\hline 11 & & False & Sure & False & Not sure \\
\hline 12 & & False & Not sure & True & Not sure \\
\hline 13 & & False & Not sure & False & Not sure \\
\hline 18 & \multirow{2}{*}{ Error } & False & Sure & True & Sure \\
\hline 19 & & False & Not sure & True & Sure \\
\hline 24 & $\begin{array}{l}\text { Understanding } \\
\text { the Concept }\end{array}$ & True & Sure & True & Sure \\
\hline
\end{tabular}

There were 186 students as samples, and they were divided into the experimental group and the control group with 93 people in each class. The four-tier diagnostic test items have passed the calibration process (validation, reliability, difficulty level, and discriminating power).

Kaltakci [33] adds that validity is defined as "suitability, meaning, and the specific use of researchers based on the data they collect". In this study, each item is stated in the form of Pearson Product Moment correlation, which is as follows:

$$
F_{2 y}=\frac{N(\Sigma X Y)-(z X)\left(\Sigma Y^{2}\right)}{\sqrt{\left[N\left(\Sigma X^{2}\right)-(\Sigma X)\right] 2\left(\mathrm{~N}\left(\Sigma Y^{2}\right)-\left(\Sigma Y^{2}\right)\right]^{2}}}
$$

Information:

$$
\begin{aligned}
& \mathrm{N}=\text { Number of respondents } \\
& \mathrm{X}=\text { The score of each question } \\
& \mathrm{Y}=\text { Total score } \\
& \text { rxy }=\text { Product Moment correlation coefficient }
\end{aligned}
$$

The Interpretation of the correlation coefficient is expressed in table 2.

TABLE II. QUESTION VALIDITY CATEGoRIES

\begin{tabular}{|l|l|}
\hline \multicolumn{1}{|c|}{ Correlation Coefficient Interval } & \multicolumn{1}{c|}{ Criteria } \\
\hline $0,80<\mathrm{r}_{\mathrm{xy}}<1,000$ & Very good \\
\hline $0,60<\mathrm{r}_{\mathrm{xy}}<0,799$ & Good \\
\hline $0,40<\mathrm{r}_{\mathrm{xy}}<0,599$ & Enough \\
\hline $0,20<\mathrm{r}_{\mathrm{xy}}<0,399$ & less \\
\hline $0,00<\mathrm{r}_{\mathrm{xy}}<0,199$ & very less \\
\hline
\end{tabular}

The reliability method used is the Internal Consistency Method. The test reliability coefficient is determined using the Kuder Richardson 20 (KR-20) formula in the form of multiple practice questions. The following is the form of the Kuder Richardson 20 formula:

$$
r_{20}=\left(\frac{n}{n-1}\right)\left(1-\frac{\sum p q}{s^{2}}\right)
$$

Information:

$\mathrm{n}=$ The number of research samples

$\mathrm{p}=$ The proportion of one item correct answers

$\mathrm{q}=$ The proportion of answers to one item

$s^{2}=$ Total variance

$\mathrm{r}_{20}=$ Instrument reliability coefficient

Then, the results of using the KR20 formula will be interpreted in table 3 . 
TABLE III. PRODUCT MOMENT CORRELATION CRITERIA

\begin{tabular}{|l|l|}
\hline \multicolumn{1}{|c|}{ Correlation Figures } & \multicolumn{1}{c|}{ Criteria } \\
\hline $0,80<\mathrm{r}_{20}<1,00$ & Very good \\
\hline $0,60<\mathrm{r}_{20}<0,80$ & Good \\
\hline $0,40<\mathrm{r}_{20}<0,60$ & Enough \\
\hline $0,20<\mathrm{r}_{20}<0,40$ & Less \\
\hline $0,00<\mathrm{r}_{20}<0,20$ & Very less \\
\hline
\end{tabular}

The level of difficulty is the ratio of students who answered the questions correctly and the number of students who answered the questions. The use of a difficulty level this research uses the Nitko formula:

$$
p=\frac{2 B}{N}
$$

Information:

$\mathrm{p}=$ Difficulty index.

$\mathrm{B}=$ The number of participants answered correctly

$\mathrm{N}=$ Number of participants answering the test

Furthermore, the results of using equation above are interpreted in table 4.

TABLE IV. DIFFICULTY LEVEL INDEX CRITERIA

\begin{tabular}{|l|l|}
\hline \multicolumn{1}{|c|}{ Index Distance } & \multicolumn{1}{c|}{ Criteria } \\
\hline $0,00<\mathrm{p}<0,20$ & Very difficult \\
\hline $0,21<\mathrm{p}<0,40$ & Difficult \\
\hline $0,41<\mathrm{p}<0,60$ & Moderate \\
\hline $0,61<\mathrm{p}<0,80$ & Easy \\
\hline $0,81<\mathrm{p}<1,00$ & Very easy \\
\hline
\end{tabular}

TABLE VI. RESULTS OF RESEARCH INSTRUMENT TRIALS

\begin{tabular}{|c|c|c|c|c|c|c|c|c|}
\hline \multirow{2}{*}{ NO } & \multicolumn{2}{|c|}{ Level of Difficulty } & \multicolumn{2}{|c|}{ Discernment } & \multicolumn{2}{|c|}{ Validity } & \multirow{2}{*}{ Reliability } & \multirow{2}{*}{ Decision } \\
\hline & Value & Category & Value & Category & Value & Category & & \\
\hline 1 & 0.534 & Moderate & 0.545 & Very Different & 0.707 & Good & \multirow{15}{*}{0.889} & Good question \\
\hline 2 & 0.554 & Moderate & 0.625 & Very Different & 0.710 & Good & & Good question \\
\hline 3 & 0.568 & Moderate & 0.452 & Very Different & 0.679 & Good & & Good question \\
\hline 4 & 0.500 & Moderate & 0.566 & Very Different & 0.708 & Good & & Good question \\
\hline 5 & 0.571 & Moderate & 0.594 & Very Different & 0.702 & Good & & Good question \\
\hline 6 & 0.518 & Moderate & 0.529 & Very Different & 0.752 & Good & & Good question \\
\hline 7 & 0.559 & Moderate & 0.559 & Very Different & 0.731 & Good & & Good question \\
\hline 8 & 0.576 & Moderate & 0.646 & Very Different & 0.686 & Good & & Good question \\
\hline 9 & 0.568 & Moderate & 0.554 & Very Different & 0.765 & Good & & Good question \\
\hline 10 & 0.541 & Moderate & 0.523 & Very Different & 0.666 & Good & & Good question \\
\hline 11 & 0.579 & Moderate & 0.559 & Very Different & 0.700 & Good & & Good question \\
\hline 12 & 0.578 & Moderate & 0.483 & Very Different & 0.720 & Good & & Good question \\
\hline 13 & 0.569 & Moderate & 0.553 & Very Different & 0.715 & Good & & Good question \\
\hline 14 & 0.568 & Moderate & 0.591 & Very Different & 0.742 & Good & & Good question \\
\hline 15 & 0.509 & Moderate & 0.522 & Very Different & 0.771 & Good & & Good question \\
\hline
\end{tabular}

After the student has received treatment. Then, the students' misconceptions data were analyzed based on the following equation:
This index determines the difference in students' high and low abilities called the distinguishing power of the test question instrument. The following is the formula for the power difference index of the test question instruments:

$$
D=\frac{B_{a}}{N_{a}}-\frac{B_{b}}{N_{b}}
$$

Information:

$\mathrm{D}=$ Distinguishing power

$\mathrm{NA}=$ The number of participants in the top group

$\mathrm{NB}=$ Number of participants in the lower group

$\mathrm{BA}=$ The number of participants in the top group answer right $\mathrm{BB}=$ Number of participants in the lower group answered wrong

The interpretation of equation is shown in table 5.

TABLE V. DISTINGUISHING POWER CRITERIA

\begin{tabular}{|l|l|}
\hline \multicolumn{1}{|c|}{ Index Distance } & \multicolumn{1}{c|}{ Criteria } \\
\hline Under 0,10 & Doubtful item \\
\hline $0,11<\mathrm{D}<0,20$ & Does not differentiate \\
\hline $0,21<\mathrm{D}<0,30$ & Moderate \\
\hline $0,31<\mathrm{D}<0,40$ & Different \\
\hline $0,41<\mathrm{D}<1,00$ & Very Different \\
\hline
\end{tabular}

The reliability score was high (0.889) and 15 out of 20 items in the feasibility test were ready to use. 
7.

With the provisions of the reduced value category in table

TABLE VII. CRITERIA FOR QUANTITY REDUCTION MISCONCEPTIONS

\begin{tabular}{|l|l|}
\hline \multicolumn{1}{|c|}{ limit } & \multicolumn{1}{c|}{ Criteria } \\
\hline$\Delta \mathrm{M}>0.7$ & High \\
\hline $0.3<\Delta \mathrm{M}<0.7$ & medium \\
\hline$\Delta \mathrm{M}<0.3$ & Low \\
\hline
\end{tabular}

The implementation stages in the study began with the provision of four tier tests to students who had been determined to find out misconceptions of chemical bonds. Then, researchers provide learning using the $\mathrm{CC}$ and $\mathrm{POE}$ models to reduce misconceptions about students. Furthermore, at the end of the lesson, a final test using a four tier test is given. After that, the understanding data obtained through the implementation stage were analyzed using the normality test, homogeneity test, and $\mathrm{t}$ test.

\section{RESULTS AND DISCUSSIONS}

\section{A. Differences in Derivation of Misconceptions Quantity} between the Experimental Group and the Control Group

The derivation of students' misconceptions was calculated by the equation of Kurniawan et al. [34], as shown in Table 8.

TABLE VIII. RECAPITULATION OF MISCONCEPTIONS DERIVATION QUANTITY IN THE EXPERIMENTAL AND CONTROL GROUP

\begin{tabular}{|l|l|l|l|l|}
\hline \multirow{2}{*}{ Sample } & \multicolumn{2}{|c|}{ Misconception } & \multirow{2}{*}{$\Delta M$} & information \\
\cline { 2 - 5 } & \multicolumn{1}{|c|}{ Before } & After & & \\
\hline Experiment & 44.0 & 15.8 & 0.64 & Moderate \\
\hline Control & 45.7 & 43.3 & 0.05 & Low \\
\hline
\end{tabular}

Based on Table 8 it shows that the average derivation in the experimental group's misconception is higher (moderate category) than the control group's (low category). Gurmu [35] revealed that the dominance of students' learning methods such as memorising chemistry concepts without observing, proving, and experiencing how a concept is formed creates misconceptions. The conventional model is a method that only makes students passive and teachers active. The students receive knowledge from the teacher without any proof of a given concept [36]. Furthermore, the misconception also comes from the learning environment, so it is hard to remove [37]. In general, the stages of the conventional model are: First, the teacher will explain the concept followed by the instruction to take a note towards the explanations. Then, the students will be given some exercises. This situation makes the classroom atmosphere monotonous and results in less effective learning of abstract chemical bond concepts [38]. The experimental group got treatment in the form of constructivism learning models such as CC and POE, which can reduce the number of chemical bond misconceptions. The students' conceptual understanding is obtained from meaningful learning in the $\mathrm{CC}$ and POE learning models. These constructivism learning models can form a good understanding of students so that the decrease in the number of chemical bonds' misconceptions is higher than the control groups'. The normality and homogeneity test results to determine the difference in the decrease of misconceptions between the experimental group and the control group is shown in table 9.

The results of statistical data analysis from the four-tier test in the experimental group and control group based on Table 2 by using SPSS version 22 software indicate that the data are not normally distributed and are not homogeneous which have a $\mathrm{Sig}<.05$. However, the $\mathrm{Z}_{\text {count }}>\mathrm{Z}_{\text {table }}$ in the discriminating power test differs between the experimental and the control group, so it can be concluded that it is significant.

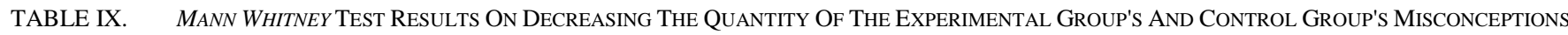

\footnotetext{
$*)=$ Kolmogorov-Smirnov test, if Sig $>.05$ (Normal)

$* *$ ) $=$ Levine's test, if Sig $>.05$ (Homogeneous)

$* * *)=\mathrm{t}$ test or Mann Whitney test, if Sig. $\mathrm{p}>.05$
}

Information:

\begin{tabular}{|l|l|l|l|l|l|l|l|}
\hline \multirow{2}{*}{ No. } & \multirow{2}{*}{ Class } & \multirow{2}{*}{ Average } & Normality*) & \multirow{2}{*}{ Homogeneity $* *)$} & \multicolumn{2}{|c|}{ Z value $* * *)$} & \multirow{2}{*}{ Information } \\
\cline { 1 - 1 } & & Experiment & 0.64 & Abnormal $(0.021)$ & \multirow{2}{*}{ Not Homogent } & Z table & \\
\hline 2 & Control & 0.05 & Normal $(0.117)$ & & Significant \\
\hline
\end{tabular}

\section{B. The Decreasing of Misconceptions in Each Sub-Topic}

The results of the chemical bond misconceptions in each sub-topic can be seen in table 10 . 
TABlE X. ReCAPITUlation OF The Misconceptions DeCREASE For EACH SUB TOPIC

\begin{tabular}{|c|c|c|c|c|}
\hline \multirow{2}{*}{ Sub Topic } & \multicolumn{4}{|c|}{ Experiment Group } \\
\hline & Before & After & $\Delta M$ & Information \\
\hline $\begin{array}{l}\text { Lewis } \\
\text { structure }\end{array}$ & 48.2 & 14.0 & 0.71 & High \\
\hline Ionic Bonds & 49.2 & 16.4 & 0.67 & Moderate \\
\hline $\begin{array}{l}\text { Covalent } \\
\text { Bonds }\end{array}$ & 46.6 & 12.7 & 0.73 & High \\
\hline $\begin{array}{l}\text { Polar And } \\
\text { Non Polar } \\
\text { Covalent } \\
\text { Compounds }\end{array}$ & 44.7 & 19.4 & 0.57 & Moderate \\
\hline $\begin{array}{l}\text { Metal } \\
\text { Bonds }\end{array}$ & 44.7 & 17.7 & 0.60 & Moderate \\
\hline $\begin{array}{l}\text { Inter- } \\
\text { Molecular } \\
\text { Forces } \\
\end{array}$ & 47.1 & 18.0 & 0.62 & Moderate \\
\hline $\begin{array}{l}\text { Molecular } \\
\text { Shape }\end{array}$ & 42.9 & 14.5 & 0.66 & Moderate \\
\hline $\begin{array}{l}\text { Physical } \\
\text { Properties } \\
\text { of } \\
\text { Compounds }\end{array}$ & 44.5 & 16.8 & 0.62 & Moderate \\
\hline \multirow{2}{*}{ Sub Topic } & \multicolumn{4}{|c|}{ Control Group } \\
\hline & Before & After & $\Delta M$ & Information \\
\hline $\begin{array}{l}\text { Lewis } \\
\text { structure }\end{array}$ & 52.5 & 41.0 & 0.22 & Low \\
\hline $\begin{array}{l}\text { Ionic } \\
\text { Bonds }\end{array}$ & 49.3 & 42.2 & 0.14 & Low \\
\hline $\begin{array}{l}\text { Covalent } \\
\text { Bonds }\end{array}$ & 50.2 & 44.8 & 0.11 & Low \\
\hline $\begin{array}{l}\text { Polar And } \\
\text { Non Polar } \\
\text { Covalent } \\
\text { Compounds }\end{array}$ & 48.0 & 43.1 & 0.10 & Low \\
\hline $\begin{array}{l}\text { Metal } \\
\text { Bonds } \\
\end{array}$ & 51.4 & 45.1 & 0.12 & Low \\
\hline $\begin{array}{l}\text { Inter- } \\
\text { Molecular } \\
\text { Forces } \\
\end{array}$ & 47.4 & 42.4 & 0.11 & Low \\
\hline $\begin{array}{l}\text { Molecular } \\
\text { Shape }\end{array}$ & 47.8 & 45.8 & 0.04 & Low \\
\hline $\begin{array}{l}\text { Physical } \\
\text { Properties } \\
\text { of } \\
\text { Compounds }\end{array}$ & 46.5 & 42.3 & 0.09 & Low \\
\hline
\end{tabular}

In the experimental group, the high category of misconceptions reduction was found in the Lewis structure by 0.7 and covalent bonds sub-topic by 0.67 , while the other subtopic was in the medium category (Table 10). The experimental group experienced $\mathrm{CC}$ and POE learning models. At the beginning of the learning process, the teacher discovered the students' initial ideas. This treatment had a good impact on students' conceptual understanding so that the reduction of misconceptions in the experimental group was better than the control group. Adzape and Akpoghol [34] stated that constructivism learning, such as the CC and POE models could correct chemistry misconceptions, and its use is beneficial in teaching and learning activities. The POE model can create active learners in expressing and developing their ideas [37].
Zakiyah et al. [38] added that this model could decrease students' misconceptions and increase their good conceptual understanding. The decrease of misconception was low for all sub-topics experienced by the students in the control group (Table 3).

The use of the CC model was very effective in reducing the misconceptions of covalent bonds as used by Putri and Sukarmin [39]. They used the model in the form of conceptual change text and the framework could solve students' daily life problems. The $\mathrm{CC}$ and POE models required learners to confront and evaluate their concept based on intelligence, credibility, and usefulness. Barlia [40] mentioned several stages in the CC model, namely addition, rearrangement/restructuring, and replacement. This model was also suggested by Nadelson et al. [41] for science education teachers because it is effective in changing students' concept. The learning by using CC and POE learning models on all the sub-topics in Table 3 shows a significant decrease in the misconceptions quantity. Chen et al. [42] suggested further collaboration in $\mathrm{CC}$ and POE models use to overcome misconceptions in other scientific topics. The combination of $\mathrm{CC}$ and POE models are proven in this research to reduce students' misconceptions.

\section{CONCLUSION}

Based on this research, it can be concluded that combined learning of CC and POE can decrease students' misconceptions in the topic of chemical bond. In addition, these learning models can improve students' understanding of concepts.

\section{REFERENCES}

[1] Ayas. Alipasa and Kibar. Zeynep Bak, "Implementing Of A Worksheet Related To Physical And Chemical Change Concepts", Procedia Social and Behavioral Sciences. 2010, Vol. 2, pp. 733-738.

[2] Omwirhiren. Efe M, "An Analysis Of Misconceptions In Organic Chemistry Among Selected Senior Secondary School Students In Zaria Local Government Area Of Kaduna State, Nigeria", International Journal of Education and Research, 2016, Vol. 4, pp. 247-266.

[3] Hermann. Jean-Marie, "Fundamentals And Misconceptions In Photocatalysis", Journal of Photochemistry and Photobiology A: Chemistry, 2010, Vol. 216, pp. 85-93.

[4] Kay. Chu Chit and Yiin. Hong Koh, "Misconception In The Teaching Of Chemistry In Secondary Schools In Singapore \& Malaysia”, Proceedings Of The Sunway Academic Conference, Department Of PreUniversity Programmes Sunway College Johor Bahru, 2010, vol. 1, pp. $1-10$.

[5] M. Meltafina, W. Wiji and S. Mulyani, "Misconceptions And Threshold Concepts In Chemical Bonding” J. Phys.: Conf. Ser, 2018, vol.1157, pp. $1-5$.

[6] Ozmen. Haluk, "Some Student Misconceptions in Chemistry: A Literature Review of Chemical Bonding”, Journal of Science Education and Technology, 2004, vol. 13, pp. 147-159.

[7] K. V. F. Fatokun, "Instructional Misconceptions Of Prospective Chemistry Teachers in Chemical Bonding", International Journal of Science and Technology, 2016, vol. 7, pp. 18-24. 
[8] Fadhillah. Annisa and Salirawati. Das, "Analysis of Misconceptions of Chemical Bonding among Tenth Grade Senior High School Students Using a Two-Tier Test", AIP Conf. Proc, 2021, 080002-1-080002-7.

[9] Fahmi and Irhasyuarna. Yudha, "The Misconceptions Of Senior High School Students In Banjarmasin On Chemical Bonding", Journal of Education and Practice, 2017, vol. 8, pp. 32-39.

[10] Ikenna. Ilhuarulam Ambrose, "Remedying Students' Misconceptions In Learning Of Chemical Bonding And Spontaneity Through Intervention Discussion Learning Model (IDLM)", International Journal of Educational and Pedagogical Sciences, 2014, vol. 8, pp. 3259-3262.

[11] Parekh. Jaya Kushwaha Archana and Pare. Brijesh, "Identification Of Students Misconceptions Regarding Chemical Bonding And Their Remediation: A Study On 11th Grade Students In India”, International Journal Of Innovative Research \& Growth, 2017, vol. 4, pp. 87-93.

[12] Perez. J R Ballester Perez. M E Ballester Calatayud. M L Garcia-Lopera. R Montesinos. J V Sabater and Gil. E Trilles, "Student's Misconceptions on Chemical Bonding: A Comparative Study between High School and First Year University Students", Asian Journal of Education and eLearning, 2017, vol. 5, pp. 1-15.

[13] Sen. Senol Varoglu. Lutfiye and Yilmaz. Ayhan, "Cognitive Structures and Misconceptions with Thematic Framework: The Case of Chemical Bonding”, 2019, vol. 16, pp. 65-78.

[14] Masykuri. Mohammad Afifa. Fatiya Nurul and Ashadi, "Students' Misconceptions on Basic Concept of Redox Reaction", AIP Conf. Proc, 2019, 2194 020062-1-020062-5.

[15] H. R. Widarti A. Permanasari and S. Mulyani, "Students" Misconceptions on Titration", IOP Conf. Series: Journal of Physics: Conf. Series, 2016, vol. 812, pp. 1-6.

[16] Unal. Suat Costu. Bayram and Ayas. Alipasa, "Secondary School Students' Misconceptions of Covalent Bonding", Journal Of Turkish Science Education, 2010, vol. 7, pp. 3-29.

[17] Daminar. Nathalie L, "Remediating Filipino Engineering Students' Misconceptions Concerning Ionic Bonding Through Outcomes - Based Teaching and Learning Computer Assisted Instructional Material (OBTL-CAIM)", Journal of Engineering and Science Research, 2017, vol. 1, pp. 157-162.

[18] Cynthia J. Luxford and Bretz. Stacey Lowery, "Development of the Bonding Representations Inventory To Identify Student Misconceptions about Covalent and Ionic Bonding Representations", J. Chem. Educ, 2014, vol. 91, pp. 312-320.

[19] Hanson. R Sam. A and Antwi. V, "Misconceptions Of Undergraduate Chemistry Teachers About Hybridisation", African Journal of Educational Studies in Mathematics and Sciences, 2012, vol. 10, pp. 4554.

[20] Demircioglu. Gökhan, "An Investigation Of Chemistry Student Teachers' Understanding Of Chemical Equilibrium", International Journal on New Trends in Education and Their Implications, 2013, vol. 4, pp. 192-199.

[21] Pekmez. Esin Sahin, "Using Analogies To Prevent Misconceptions About Chemical Equilibrium”, Asia-Pacific Forum on Science Learning and Teaching, 2010, vol. 11, pp. 1-35.

[22] Habiddin and Page Mary. Elizabeth, "Development and Validation of a Four-Tier Diagnostic Instrument for Chemical Kinetics (FTDICK)", Indones. J. Chem., 2019, vol. 3, pp. 720-736.

[23] Karous. Hamad Nihant. Brigitte and Leyh. Bernard 2017 Learning Chemical Kinetics At Secondary School Level: Misconceptions And Alternative Approach European Science Education Research Association (ESERA), 2019, vol. 17, pp. 1-4.

[24] Yee Lai. Mun and Wong. Jeffrey P. "Revisiting Decimal Misconceptions From A New Perspective: The Significance Of Whole Number Bias In The Chinese Culture", Journal of Mathematical Behavior, 2017, vol. 47, pp. 96-108.

[25] Durkin. Kelley and Johnson. Bethany Rittle, "Diagnosing Misconceptions: Revealing Changing Decimal Fraction Knowledge", Learning and Instruction, 2015, vol. 37, pp. 21-29.
[26] Kurniawan. Yudi Suhandi. Andi and Hasanah. Lilik, "The Influence Of Implementation Of Interactive Lecture Demonstrations (ILD) Conceptual Change Oriented Toward The Decreasing Of The Quantity Students That Misconception On The Newton's First Law", Proceedings of International Seminar on Mathematics, Science, and Computer Science Education (MSCEIS 2015), AIP Conf. Proc., 2015, vol. 1708, pp. 1-5.

[27] Muis. K.R, Sinatra. G.M, Pekrun. R, Winne, P.H. Trevors. G, Losenno K.M, . . . Munzar. B, "Epistemic Emotions And Conceptual Change", Contemporary Educational Psychology, 2018, doi: https://doi.org/10.1016/j.cedpsych.2018.10.001.

[28] Chen. Chien-Hsien, and She. Hsiao-Ching, "The Impact of Recurrent On-line Synchronous Scientific Argumentation on Students' Argumentation and Conceptual Change", Educational Technology dan Society, 2012, vol. 15, no. 1, pp. 197-210.

[29] Novak. Kerry, Mandin. Henry, Wilcox. Elizabeth, and McLaughlin. Kevin, "Using A Conceptual Framework During Learning Attenuates The Loss Of Expert-Type Knowledge Structure", BMC Medical Education, 2006, vol. 6, no. 37, pp. 1-8, doi: 10.1186/1472-6920-6-37.

[30] Gurmu. Abayneh L, "Early Chemistry Misconceptions: Status and Implication on Quality of Primary Education in Ethiopia", Internationa Journal of Advanced Research in Chemical Science (IJARCS), 2016, vol. 3, pp. 36-43.

[31] Sahin. Cigdem, Ipek. Hava, and Ayas. Alipasa, "Student's Understanding Of Light Concept Primary School: A Cross-Age Study", Asia-Pasific Forum On Science Learning And Teaching, 2008, vol. 9, no. 1, pp. 1-19.

[32] Usmeldi, "The Effectiveness Of Research-Based Physics Learning Module With Predict-Observe-Explain Strategies To Improve The Student's Competence", IOP Conf. Series: Journal of Physics: Conf. Series, 2018, vol. 1013, doi :10.1088/1742-6596/1013/1/012041.

[33] Kaltakci. Derya, "Development And Application Of A Four-Tier Test To Assess Pre-Service Physics Teachers" Misconceptions About Geometrical Optics", Secondary Science And Mathematics Education, The Graduate School Of Natural And Applied Sciences, Middle East Technical University, Turkey, 2012.

[34] Adzape. J N and Akpoghol. T V, "Correcting St Udents' Chemical Misconcept Ions Based On Two Conceptual Change Strategies And T Heir Effect On Their Achievement" IOSR Journal of Research \& Method in Education (IOSR-JRME), 2015, vol. 5, pp. 58-65.

[35] Glykos. Nicholas M, "The 11th Misconception? CBE-Life Sciences Education", 2011, vol. 10, pp. 1-2

[36] Uce. Musa and Ceyhan. Ilknur, "Misconception in Chemistry Education and Practices to Eliminate Them: Literature Analysis", Journal of Education and Training Studies, 2019, vol. 7, pp. 202-208.

[37] Dewantoro. Ragil Sugeng Suabndi and Fajaroh. Fauziatul, "Misconception Identification Using Two-Tier Test and POE Strategy to Improve Mass Balance Topic Mastery in Industrial Chemistry Vocational High School", Jurnal Pendidikan Sains, 2017, vol. 5, pp. 127-134.

[38] Zakiyah. Imroatuz Widodo. Wahono and Tukiran, "Implementation of Predict-Observe-Explain (POE) Strategy to Reduce Misconception in Thermochemistry", International Journal for Educational and Vocational Studies, 2019, vol. 1, pp. 754-759.

[39] Putri. Sovranita Ramadhani Setaiwan and Sukarmin, "Software Development to Reduce Misconceptions Using Conceptual Change Text Strategy on Chemical Bonding", International Journal of Chemistry Education Research, 2020, vol. 4, pp. 10-16.

[40] Barlia. Lily, "Patterns of Conceptual Change Process in Elementary School Students' Learning of Science", Journal of Turkish Science Education, 2016 vol. 13, pp. 49-60.

[41] Nadelson. Louis S Taasoobshirazi. Gita Heddy. Benjamin C Johnson. Marcus and Jones. Suzanne, "Conceptual Change in Science Teaching and Learning: Introducing the Dynamic Model of Conceptual Change", International Journal of Educational Psychology, 2018, vol. 7, pp. 151195.

[42] Chen. Yu-Lung Pan. Pei-Rong Sung. Yao-Ting and Chang. Kou-En, "Correcting Misconceptions On Electronics: Effects Of A SimulationBased Learning Environment Backed By A Conceptual Change Model", Educational Technology \& Society, 2013, vol. 16, pp. 212-227. 